Supporting Information

\title{
Detection of in situ Early Corrosion on Polymer-Coated Metal Substrates
}

\author{
Dwaine A. Braasch*, Mathew Gillis, Monoj Pramanik*, Richard C. Ferguson, David Delatte, Michael Blanton \\ and James Wayne Rawlins* \\ School of Polymers and Engineering, The University of Southern Mississippi, 118 College Drive \#5217, \\ Hattiesburg, MS 39406, USA \\ Corresponding Authors: Dwaine A. Braasch* (Dwaine.braasch@usm.edu) \\ James Wayne Rawlins* (James.Rawlins@usm.edu)
}

The Supporting Information contains four tables and 10 figures that underscore the salient points of the manuscript and provide additional details of the methods employed for the fluorescence optimizations and physical property characterizations. The data collectively represent the quantitative determinants of the characterization protocol development from solvent to resin and finally to a coating and the corresponding impacts on fluorescence and $\mathrm{pH}$ responsiveness.

Solvent properties, resin solubility and rheology are presented toward the development of a solvent blend used for spray application. Details of traditional coating characterization are provided in the form of cross-hatch adhesion, pull-off adhesion, solvent, impact resistance, flexibility, internal stress, diffusivity, residual solvent composition, and oxygen permeability. Collectively all these parameters contribute to the onset and propagation of corrosion of polymer-coated metal substrates.

Also provided are the supporting fluorescence data for non-coated substrates, responses to organic base, as resin solution and free-standing film forms as well as coating thickness effects, and characterization of the effects of dry heat on fluorescein in subsequent fluorescence assays. Additional characterization is provided for the $\mathrm{pH}$ effects and concentration effects towards the optimization of the fluorescein usage conditions.

Film formation characterization is provided as density and volume changes for the thermoplastic resin from the resin solution through spray application and annealing according to the three protocols. Lastly, a detailed optical view of an engraved scribe on a polymer-coated metal substrate which represents the last step prior to the plate assembly described in Figure 3 of the main document. 
Table S1. Properties of solvents.

\begin{tabular}{|c|c|c|c|c|c|c|c|c|c|c|}
\hline & CAS & $\begin{array}{l}\text { Specific } \\
\text { Gravity } \\
(\mathrm{g} / \mathrm{mL})\end{array}$ & $\begin{array}{l}\text { Molecul } \\
\text { ar } \\
\text { Weight }\end{array}$ & $\begin{array}{l}\text { Evaporatio } \\
\mathrm{n} \quad \text { Rate } \\
(\text { ether }=1)\end{array}$ & $\begin{array}{l}\text { Refractiv } \\
\text { e Index }\end{array}$ & $\begin{array}{l}\text { Flash } \\
\text { Point } \\
{ }^{\circ} \mathrm{C}\end{array}$ & $\begin{array}{l}\text { Boiling } \\
\text { Point } \\
{ }^{\circ} \mathrm{C}\end{array}$ & $\begin{array}{l}\text { Solvent } \\
\text { Solubility in } \\
\text { Water wt.\% }\end{array}$ & $\begin{array}{l}\text { Water } \\
\text { Solubility in } \\
\text { Solvent wt.\% }\end{array}$ & $\log \mathrm{P}^{* *}$ \\
\hline MEK (Methyl ethyl ketone) & $78-93-9$ & .802 & 72.11 & 3.1 & 1.3788 & -8.9 & 79.6 & 22.3 & 12.5 & .74 \\
\hline Cyclohexanone & $108-94-1$ & .948 & 98.14 & 39.3 & 1.447 & 43.9 & 155.7 & 2.3 & 8 & 1.4 \\
\hline $\begin{array}{lr}\text { EEP } & \text { (Ethyl } \\
\text { Ethoxypropionate) }\end{array}$ & $763-69-9$ & .95 & 146.19 & 98.3 & 1.407 & 57.7 & 168.5 & 2.9 & 2.2 & -0.66 \\
\hline JPC (propylene carbonate) & $108-32-7$ & 1.200 & 102.09 & $<22360$ & 1.419 & 135 & 242 & 23 & 8 & -.41 \\
\hline
\end{tabular}

* Denotes value determine with a Model CL800 Digital Clamp Meter AC/DC Auto-Ranging Klein Tools. ** Data obtained from http://www.molinspiration.com. All other data obtained from Eastman solvent selector chart http://www.eastman.com/Literature_Center/S/SOL030.pdf

\begin{tabular}{|c|c|c|c|c|c|c|c|c|c|}
\hline & H-bond & Nonpolar & Polar & Total & $\begin{array}{l}\text { Electrical } \\
\text { Resistance } \\
\text { (Mega-? })\end{array}$ & Dielectric Constant & $\begin{array}{l}\text { Surface } \\
\text { Tension } \\
\left(\text { dynes } / \mathrm{cm}^{2} \text { ) }\right.\end{array}$ & $\begin{array}{l}\text { Molar Volume } \\
\left(\mathrm{cm}^{3} / \text { mole }\right)\end{array}$ & $\begin{array}{l}\text { Polar } \\
\text { Surface } \\
\text { Area** }\end{array}$ \\
\hline $\begin{array}{l}\text { MEK (Methyl ethyl } \\
\text { ketone) }\end{array}$ & 5.1 & 15.5 & 9.0 & 18.6 & 0.2 & 18.5 & 24.6 & 90.2 & 17.07 \\
\hline Cyclohexanone & 5.1 & 18.8 & 6.3 & 20.5 & $<0.1$ & 18.3 & 27.7 & 104.1 & 17.07 \\
\hline $\begin{array}{l}\text { EEP (Ethyl 3- } \\
\text { Ethoxypropionate) }\end{array}$ & 8.8 & 16.2 & 3.3 & 18.6 & 20.0 & NA & 27.0 & 154.7 & 55.77 \\
\hline $\begin{array}{l}\text { JPC (propylene } \\
\text { carbonate) }\end{array}$ & 4.1 & 20.1 & 18.0 & 27.2 & $11.9^{*}$ & 65 & 41.9 & 85.3 & 35.54 \\
\hline
\end{tabular}


a)

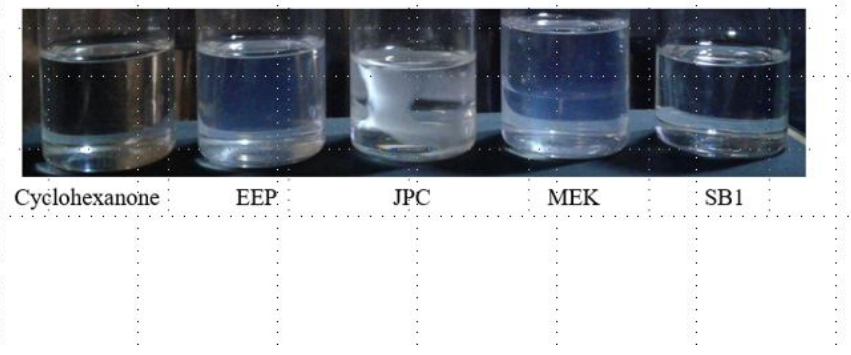

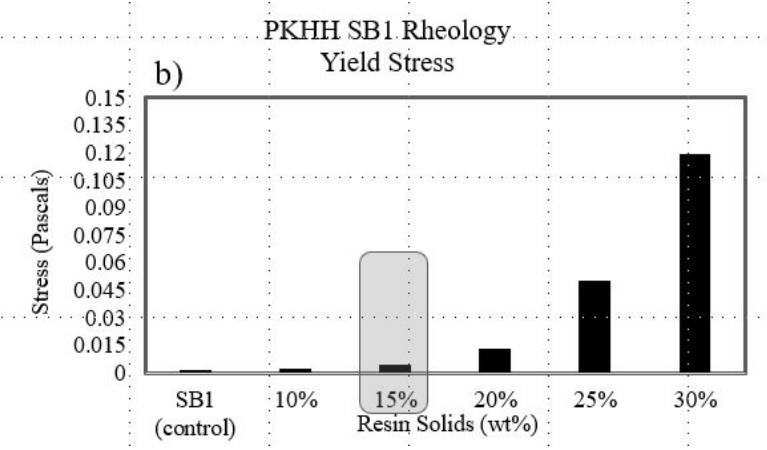

Figure S1 a) Differential solubility of 15\%PKHH in individual solvents and in the blended solvents. The resin is most soluble in cyclohexanone followed by EEP although with some turbidity remaining. The resin whitens in Jeffsol-PC, swells and phase separates. The resin in the blended solvents remains soluble and optically clear, b) Yield stress analysis of differing solids content resin solutions in SB\#1 relative to the solvent blend control. The shaded area denotes the solids used for spray application, while $25 \%$ was used for drawdown application.

Dry and Wet Adhesion Test. Pressure-sensitive tape was firmly applied over the lattice, followed by a 60 second set time, then removed sharply at $180^{\circ}$ to the coating surface. The dry test was performed on the coating as dried at room temperature. Wet samples were immersed in deionized water for 2 hours prior to testing.

\begin{tabular}{|c|c|c|}
\hline \multicolumn{3}{|c|}{ Classification of Adhesion Test Results } \\
\hline Classification & $\begin{array}{c}\text { Percent } \\
\text { area } \\
\text { removed }\end{array}$ & $\begin{array}{c}\text { Surface of cross-cut area from which Flaking } \\
\text { has occurred for six parallel cuts and } \\
\text { adhesion range by percent }\end{array}$ \\
\hline 5B & $0 \%$ & \\
\hline 4B & $<5 \%$ & \\
\hline 3B & $4-5 \%$ & \\
\hline 2B & $15-35 \%$ & \\
\hline 1B & $35-65 \%$ & \\
\hline $0 \mathrm{~B}$ & $>65 \%$ & \\
\hline
\end{tabular}

Figure S2. Clarification of dry/wet adhesion test results. 
Pull-off Adhesion Test. The adaptors for the load frame used in pull-off testing were customized to hold a coated panel on the bottom with an Elcometer $20 \mathrm{~mm}$ stud on the top. Prior to test, studs were prepared by abrading the surface first with 60 grit sandpaper and then with Scotch Brite ${ }^{\circledR}$ pads. Before adhering the studs to the panel, the coating was also abraded with Scotch Brite. Studs were adhered to the coating surface with Scotch Weld D460 epoxy adhesive and applied by hand. The adhesive was cured for 24 hours prior to testing.

Solvent resistance test. The rounded end of a 2-lb ballpeen hammer was covered with cheesecloth and soaked with methyl ethyl ketone. The solvent-soaked cloth-covered end was brought in contact with the coating surface and rubbed back and forth (one double rub) without applying downward pressure on the hammer. The process was concluded, and the number recorded, when the apparatus had rubbed through the coating to the substrate (i.e. prominent mark of damage/loss of coating from substrate on rubbed zone).

Impact resistance test. Test panels were placed in the apparatus with the coated side facing up for direct impact resistance measurement. The indenter was gently lowered onto the panel while the weight was raised and dropped from a known height. The process was repeated to determine the height at which failure occurred. Coating failure was indicated by the film cracking and delaminating from the substrate. The force at which the coating passed was recorded and ranged up to 160 in-lbs. of force.

Flexibility test. The test was performed by placing the lever in the horizontal position, and the test panel between the mandrel and the drawbar with the finish side towards the drawbar. The panel was rigidly clamped adjacent to the mandrel. The lever was rolled through $180^{\circ}$ with uniform velocity to bend the specimen by approximately $135^{\circ}$. Coating elongation was determined by measuring the distance from the end of the crack to the small end of the mandrel. The mandrel diameter at which cracking ceased was recorded as the resistance to cracking value.
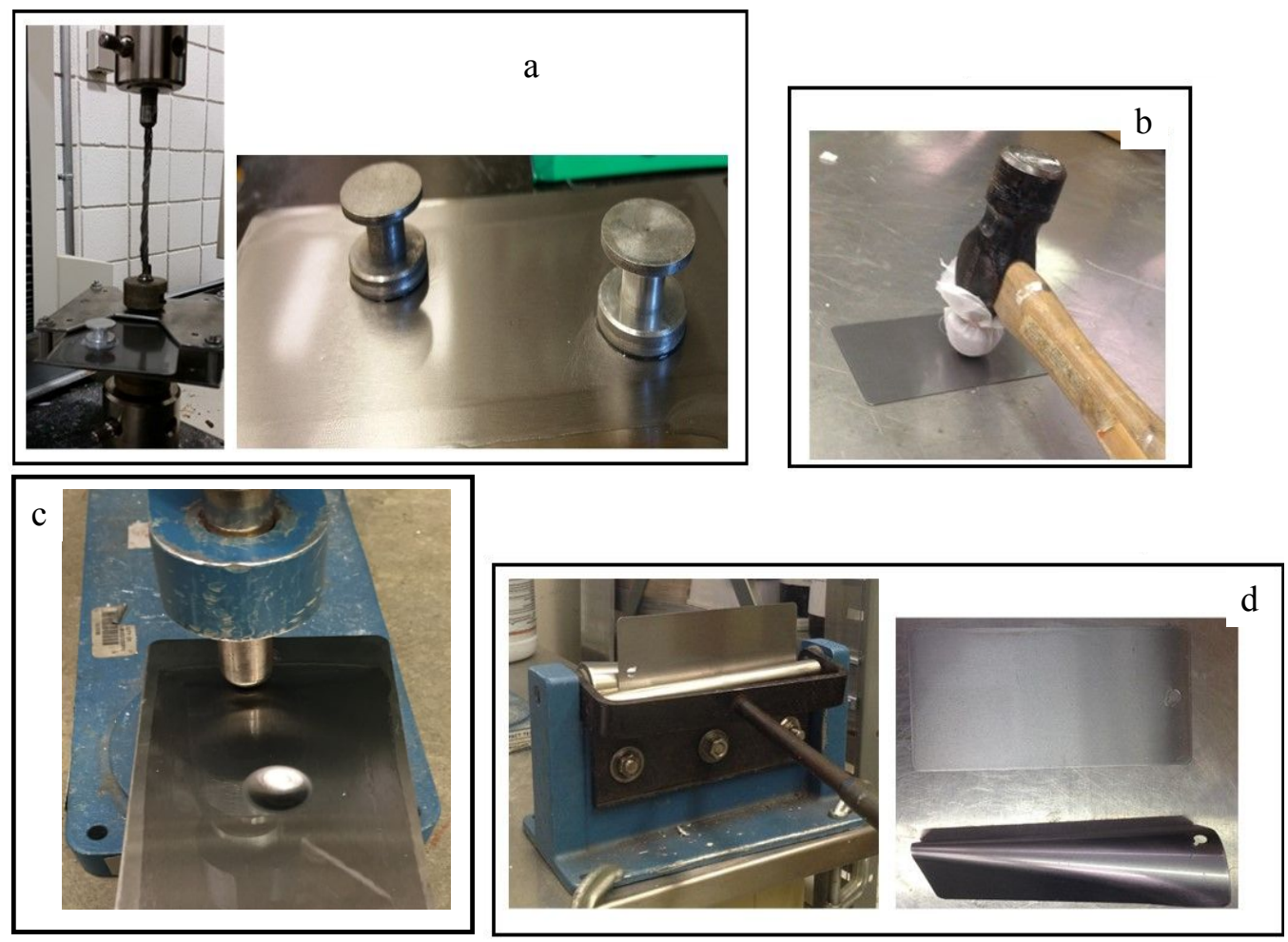

Figure S3. a) Image of specimen preparation and test set up for pull-off adhesion test of coating on QD panels, b) set up for solvent resistance (MEK double rubs) test, c) Impact resistance test, d) Mandrel flexibility test set. 
Diffusion coefficient(s) were calculated using the following equations:

$$
\begin{aligned}
& \frac{M_{t}}{M_{\infty}}=\frac{4}{L} \cdot\left(\frac{D t}{\pi}\right)^{n} \quad \text { Equation } 1 \\
& D=\left(\frac{\text { slope } \times \text { thickness }}{4} \times \sqrt{\pi}\right)^{2} \quad \text { Equation } 2
\end{aligned}
$$

Where $M_{t}$ and $M_{\infty}$ are water uptake at time $t$ and at saturation. $L$ and $D$ correspond to coating thickness and diffusion coefficient, respectively.

Internal stress test. Coatings were applied via air-assisted spray while restraining the metal strips with tape. The deflection of coated strips due to drying, volume change, and in response to wet and dry cycles was monitored optically using either a digital microscope (Keyence VHX600 digital microscope) or a digital camera (Vision HAWK Smart Camera). Measurements on the digital microscope used the built-in software while Adobe Photoshop was employed in conjunction with InduSoft Web Studio and Microscan AutoVISON programs to automate data acquisition and normalization. All digital camera photos had a measurement reference in focus. The internal stress measurement apparatus is shown in Figure S4. Internals stress $(S)$ of coating(s) was calculated from the deflection of coated strip using following equations:

$$
\begin{array}{lr}
S=\frac{h E_{s} t^{3}}{3 L^{2} c(t+c)\left(1-\gamma_{s}\right)}+\frac{h E_{c}(t+c)}{L^{2}\left(1-\gamma_{c}\right)} & \text { Equation 3 } \\
S=\frac{h E_{s} t^{3}}{3 L^{2} c(t+c)\left(1-\gamma_{s}\right)} & \text { Equation 4 }
\end{array}
$$

where $E_{s}$, is the substrate elastic modulus ( $1.93 \times 10^{4} \mathrm{MPa}$ or $2.8 \times 10^{7}$ psi for $\left.304 \mathrm{SS}\right), \gamma_{s}$ is substrate's Poisson ratio ( 0.25 for $304 \mathrm{SS}$ ), $t$ is the substrate's thickness, $L$ is the measured length to deflection ( 3 in or $80 \mathrm{~mm}$ ), $c$ is the coating thickness, $E_{c}$ is coating's elastic modulus, and $\gamma_{c}$ is the coating's Poisson ratio. $\gamma_{c}$ is very difficult to determine for a formulated coating. If the coating thickness is less than half that of the substrate, the elastic modulus and Poisson's ratio are rendered negligible and Equation 3 was used for our internal stress evaluation.
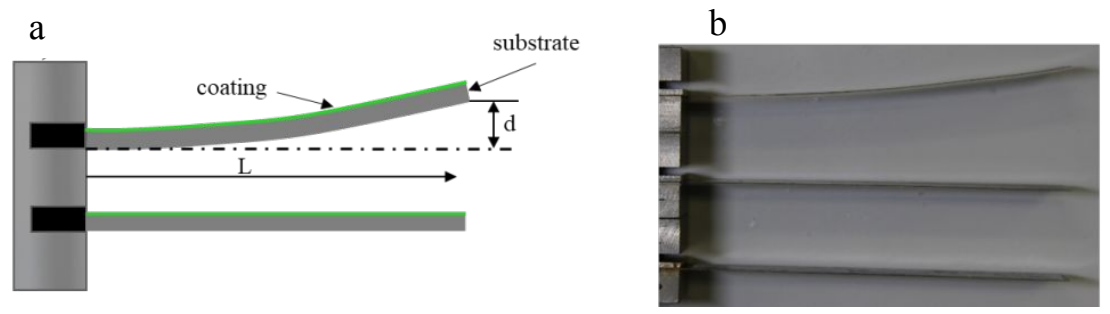

Figure S4. Internal Stress apparatus diagram a) representing a baseline (horizontal) and positive stress scenario (curved) with calculation variables $L$ and $d$ noted, b) digital image of actual samples during an internal stress experiment.

Figure S5 is an optical microscopic image of the scribe produced in a PKHH coated substrate by the Vision Express Engraver. The resulting scribe reported as coating removed $0.39 \pm 0.08 \mathrm{~mm}$ width and $11.51 \pm 0.11 \mathrm{~mm}$ in length. The total width of the scribe including mechanical disruption was $0.59 \pm 0.07 \mathrm{~mm}$ in width. Alternately, a number 11 stainless steel razor was employed in combination with a scribing jig that was placed in each well of the 6-well plate to produce a narrow scribe $0.044 \mathrm{~mm}$ in width and $10.5 \mathrm{~mm}$ in length with an extended mechanical disruption of $0.167 \mathrm{~mm}$ and $10.62 \mathrm{~mm}$ for width and length respectively. The latter scribing technique was only employed for the polished substrate experimentation described in this document. 


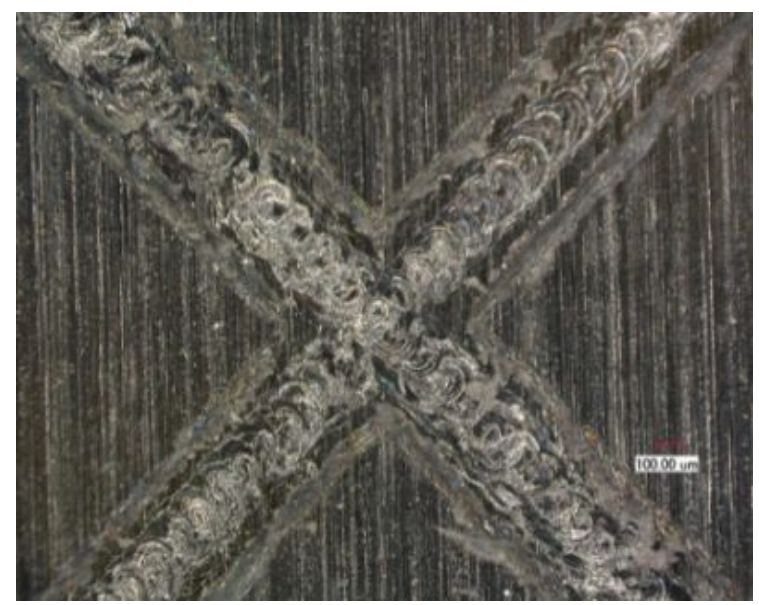

Figure S5. Optical microscope image of the scribed panel coated with PKHH.

Characterization of fluorescein in solvent/resin. Fluorescein characterization in solvent(s) and resin was conducted as a $300 \mu \mathrm{L}$ sample volume with an approximate $1 \mathrm{~cm}$ pathlength for the determination of optical properties in accordance with the Beer-Lambert Law in either $500 \mu \mathrm{L}$ glass flat bottom vial inserts for a 96 -well base plate (JG Finnergan, Vineland, NJ) or in a quartz spectrophotometer cell with a $1 \mathrm{~cm}$ pathlength in a microplate adapter both from Starna Cells, Inc. The 96-well base plate was spray painted a matte black to reduce unwanted stray fluorescence. Absorbance spectra were collected from 400 to $700 \mathrm{~nm}$ in $1 \mathrm{~nm}$ increments employing 5-25 flashes and fluorescence spectra were collected from 500 to 700 $\mathrm{nm}$ in $1 \mathrm{~nm}$ increments employing 5 flashes and a gain of 75 on either an Infinite M-1000 or M-1000 Pro multi-mode plate reader Tecan Instruments (Männedorf Switzerland) and the i-Control software.

pH Adjustment of samples. One of the first parameters to be examined for the use of fluorescein was to determine the spectral properties of fluorescein in SB1, and the two different resin concentrations relative to one another and in the presence of an organic acid or base whereby the fluorescein was in the cationic $(\mathrm{pH}<2)$, neutral $(\mathrm{pH} \sim 3.3)$, mono-anion $(\mathrm{pH}$ 5.5) or di-anion ( $\mathrm{pH}>8$ ) form (Margulies et.al. 2005). A screen of organic amine bases was performed to identify a base capable of changing the $\mathrm{pH}$ of the resin solution with a minimal loading level (Figure S6). Organic amines were selected as $\mathrm{pH}$ modifiers that are inherently more soluble within the polymer in comparison with inorganic hydroxides such as $\mathrm{NaOH}$ or $\mathrm{KOH}$ in the solvent blend/resin. It was noted that the more vaporous $\mathrm{NH}_{4} \mathrm{OH}$ could be used in the general vicinity of a fluorescein containing film to affect a $\mathrm{pH}$-based fluorescence response, however this effect is perceived to be due to the ammonia component rather than the hydroxide which has some literature support as to being less likely to absorb and penetrate the film on its own (Haagen et al. 1975). From the screening, the base $N$-methylcyclohexylamine was selected and was used as a base modifier in all subsequent experiments where controlled $\mathrm{pH}$ was relevant. Samples that required $\mathrm{pH}$ adjustment were prepared by determining the amount of acid or base required and subtracting that volume from the volume of the diluent required to attain proper loading of fluorescein, resin or both. To achieve the proper concentration for samples, stock solutions were employed at concentrations higher than the actual sample concentration. 


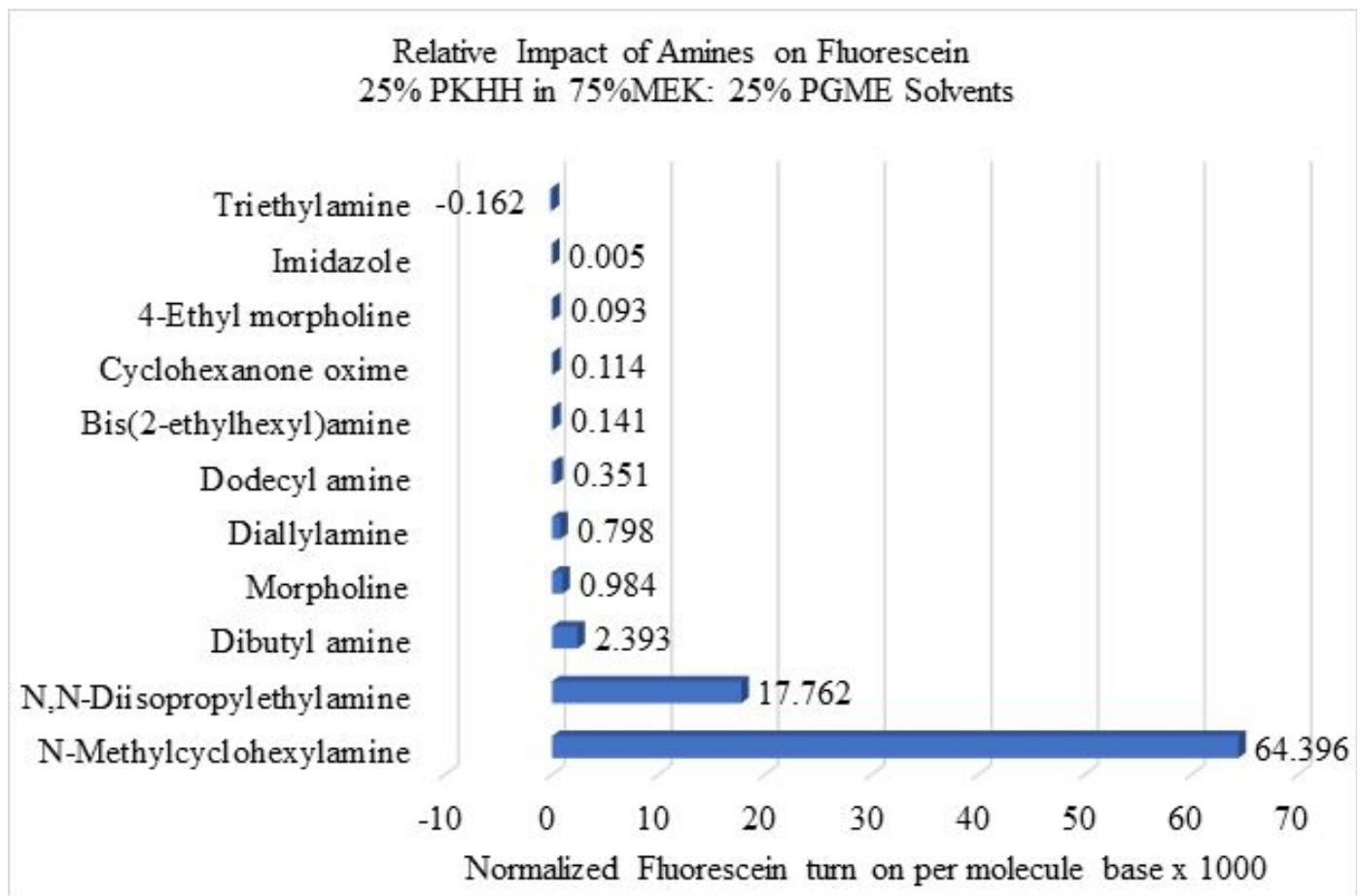

Figure S6. Relative impact of various amine base (AB) on 0.0013 wt.\% fluorescein in 25\% PKHH resin prepared in a $75: 25 \%$ solution of MEK and PGME.

Fluorescein Dose Response. For the fluorescein dose response, all solvent and resin samples were prepared by serial dilution using a master solution of solvent blend or resin which had been acid or base adjusted as the diluent and a stock solution of $0.0665 \mathrm{wt}$.\% fluorescein on a 5-gram scale. After serial dilutions were performed to attain the concentrations of interest, samples were equilibrated a minimum of 30 minutes at ambient temperature before removing $300 \mu \mathrm{L}$ aliquots for spectral analysis. Resin samples prepared in the 5-g capacity were subsequently used to generate free-standing films for absorbance and fluorescence spectroscopy.

pH Titration of PKHH resin samples. Samples were prepared for pH determination of fluorescein solution in SB1, 15\% PKHH resin and 25\% PKHH resin were determined by preparing a $0.83 \mathrm{wt}$.\% stock solution of base (NMCHA) in each of the solutions above as well as a $0.98 \mathrm{wt}$.\% solution of acid 3,6-dioxaheptanoic acid solution in SB1 and resins. Separate vials of 10 grams each were composed according to the following mass ratios $\mathrm{B}=\mathrm{b}$ ase, $\mathrm{A}=$ acid; $[10 \mathrm{~B}, 9 \mathrm{~B} 1 \mathrm{~A}, 8 \mathrm{~B} 2 \mathrm{~A}, 7 \mathrm{~B} 3 \mathrm{~A}, 6 \mathrm{~B} 4 \mathrm{~A}$, 5B5A, 4B6A, 3B7A, 2B8A, 1B9A, 10A] with additional samples prepared with higher base loading at 1.038, 1.245, 1.453, 1.66 and 3.32 wt.\%. The pH was determined with an Acumet $\AA$ AP61 portable pH meter (Fisher Scientific) with an accuTupH ${ }^{\mathrm{TM}}$ Rugged Bulb $\mathrm{pH}$ Combination Electrode and the probe was washed in SB1 without any pH adjustment between readings. 
a)

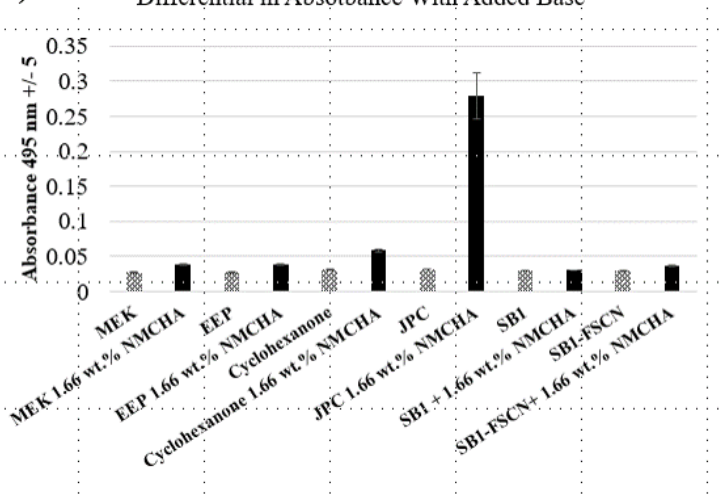

b) $\quad$ Differential in Fluoescence With Added Base

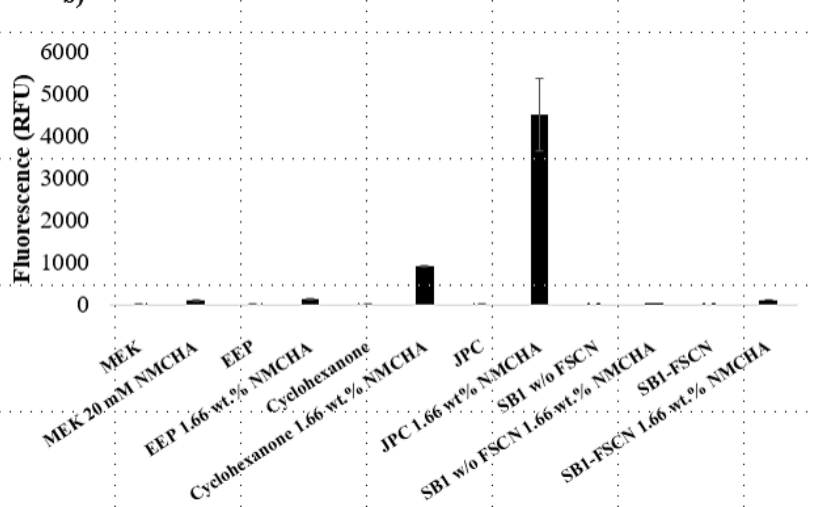

Figure S7. Basal and base modified individual solvent effects on fluorescein absorbance and emission. Absorbance a) presented as the average from $495 \mathrm{~nm} \pm 10 \mathrm{~nm}$ and fluorescence b) presented as the average of $530 \pm 5 \mathrm{~nm}$.

Effect of Temperature on Probe. Samples of dry fluorescein were weighed out into glass vials and processed according to the annealing procedures in the materials and sample preparation section. After thermal treatment, the samples were dissolved in SB1 at the 200X stock concentration and subsequently diluted to the standard 0.0013 wt.\% concentration in SB1 and 25\% PKHH resin followed by spectrophotometric and fluorescence analysis. Average values for absorbance and fluorescence at their respective wavelength ranges are presented in Figure S8. Samples prepared in SB1 from each of the thermal treatments resulted in an absorbance of $\sim 0.2$ compared to the SB1 alone $(0.02), 1 / 10^{\text {th }}$ the value. A similar trend was observed for thermally treated fluorescein samples prepared in $25 \%$ PKHH resin where the base resin material resulted in an average absorbance of 0.08 while those containing the heat-treated fluorescein averaged 1.12. Fluorescence analysis of the same samples showed the same trends (Figure S8b) with even less variation.

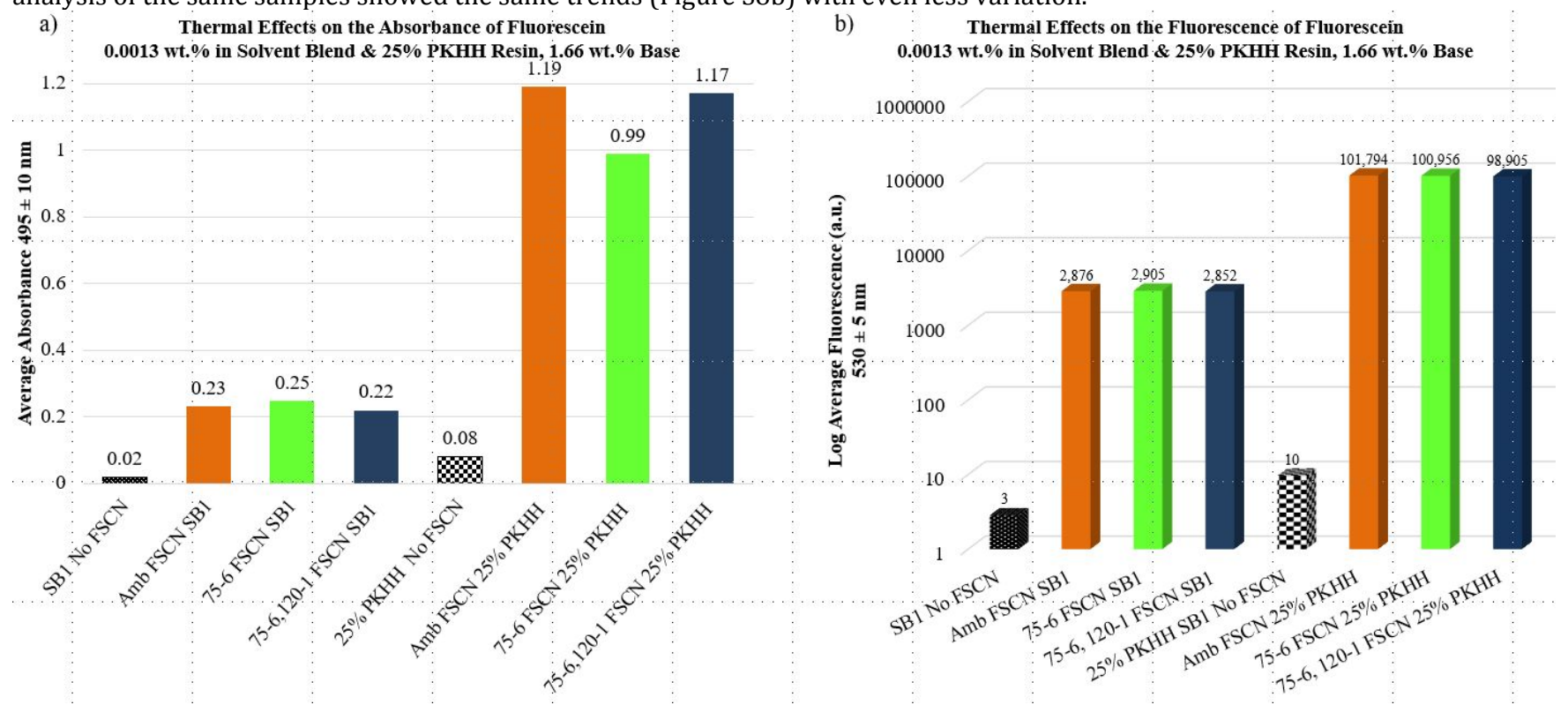

Figure S8. Average absorbance a) and fluorescence b) of fluorescein samples exposed to thermal annealing conditions and solubilized in SB1 and 25\% PKHH resin. 
Effect of Basal Substrate on Probe. Auto-fluorescence of the following series of substrates was quantified [smooth poly propylene, roughened poly propylene, 1010 steel smooth finish, 101 steel rough finish, 1010 steel QD finish, 304 stainless steel, 3030 and 2024-T3 aluminums] and demonstrated that the materials fell into three distinct groupings.

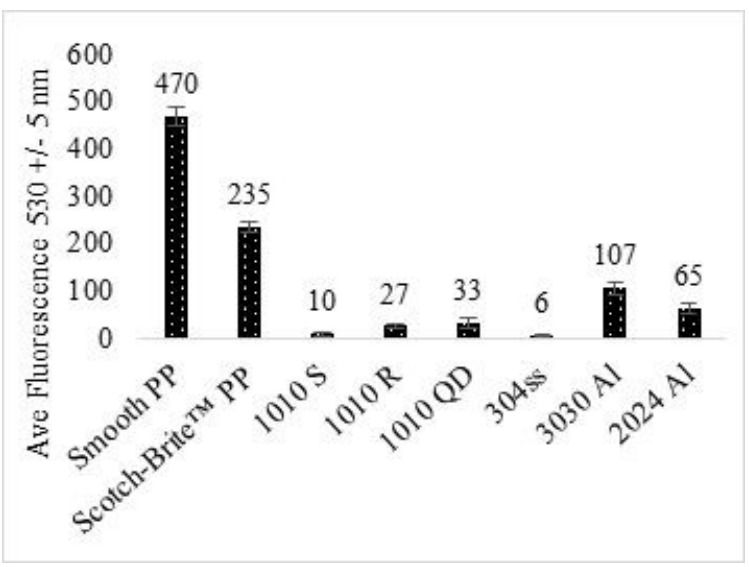

Figure S9. Basal Auto-fluorescence of various substrates.
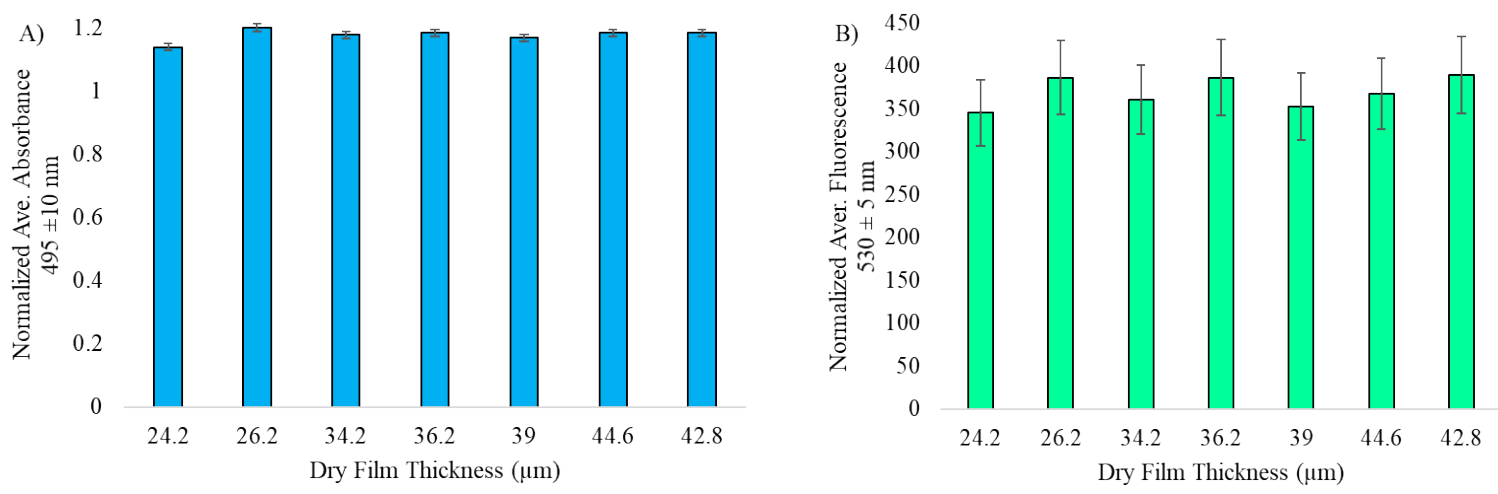

Figure S10. Absorbance a) and fluorescence b) correlation with free-standing film thickness for films drawn from $25 \%$ PKHH resin containing 0.0013 wt.\% Fluorescein and 1.66 wt.\% Base in SB1 at 4, 6, 8, 10, 12, 14, and 16 -mil wet respectively (left to right). Data were normalized by dividing data by the respective values at $700 \mathrm{~nm}$ prior to averaging ( $\mathrm{n}=6)$ and fluorescence gain was reduced to 100 . 
Table S1. Density and volume shrinkage for 15\% PKHH SB1 initially after spray application and after varying annealing procedures.

$\begin{array}{lll}\text { Sample } & \text { Density (g/cc) } & \text { Volume shrinkage (\%) } \\ \text { PKHH-on board after spray } & 1.0383 & \\ \text { PKHH-after drying at ambient } / 7 \text { days } & 1.1037 & 5.93 \\ \text { PKHH-after drying at } 75^{\circ} \mathrm{C} / 6 \mathrm{hr} . & 1.1831 & 12.24 \\ \text { PKHH-after drying at } 75^{\circ} \mathrm{C} / 6 \mathrm{~h}+120^{\circ} \mathrm{C} / 1 \mathrm{hr} . & 1.1647 & 10.85\end{array}$

Table S3. Gas Chromatography-Mass Spectroscopy relative percentage of dimethoxymethane extracted residual solvents from $\mathrm{PKHH}$ free-standing films annealed at ambient, $75^{\circ} \mathrm{C}$ and $120^{\circ} \mathrm{C}$.

\begin{tabular}{|l|l|l|l|}
\cline { 2 - 4 } \multicolumn{1}{c|}{} & Cyclohexanone & Cyclic Propylene carbonate & EEP \\
\hline Ambient & 11.11 & 45.77 & 43.12 \\
\hline $75^{\circ} \mathrm{C}$ & 25.4 & 34.41 & 40.19 \\
\hline $120^{\circ} \mathrm{C}$ & 54.29 & 10.08 & 35.64 \\
\hline
\end{tabular}

Table S4. Oxygen permeability, diffusivity and solubility of free-standing PKHH polymer films annealed at $75^{\circ} \mathrm{C}$ and $120^{\circ} \mathrm{C}$.

\begin{tabular}{|l|l|l|l|}
\hline & Permeability (Barrer) & Diffusivity $\left(\mathbf{c m}^{2} / \mathbf{s}\right)$ & Solubility $\left(\mathbf{c c} / \mathbf{a t m} \bullet \mathbf{c m}^{\mathbf{3}}\right)$ \\
\hline $75^{\circ} \mathrm{C}$ & .037 & $7.46 \mathrm{E}-9$ & .0386 \\
\hline $120^{\circ} \mathrm{C}$ & .0274 & $2.64 \mathrm{E}-9$ & .0799 \\
\hline
\end{tabular}

